HEIDI HANSSON, MARIA LINDGREN LEAVENWORTH \& ANKA RYALL (RED.)

\title{
THE ARCTIC IN
}

\section{LITERATURE FOR}

CHILDREN AND YOUNG

\section{ADULTS}

New York/London: Routledge, 2020 (237 s.)

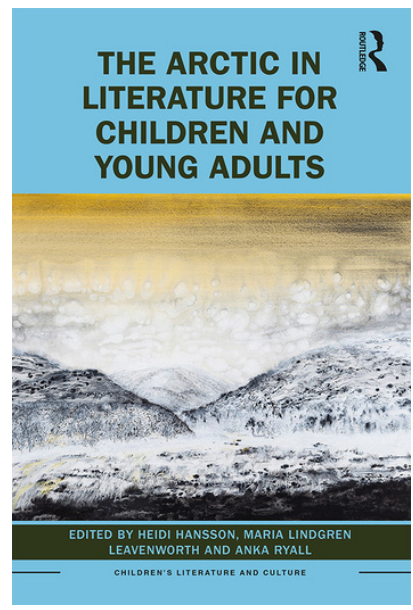

Antologien The Arctic in Literature for Children and Young Adults (2020), redigert av Heidi Hansson, Maria Lindgren Leavenworth og Anka Ryall som alle tre dessuten bidrar med hvert sitt kapittel, diskuterer fremstillinger av Arktis i barne- og ungdomslitteratur (og i film og TV), fra det tidlige 1800-tallet frem til i dag. Gjennom introduksjonen som er skrevet av Hansson og fjorten bidrag fra forskere med variert fagtilhørighet, gir antologien et viktig innblikk i hvilken rolle tekster for barn og ungdom har hatt og fortsatt har i å danne, opprettholde og utfordre arktiske myter og motiver. Den akademiske interessen for litterære og andre kulturelle fremstillinger av Arktis og det nordlige har vokst seg stadig sterkere de siste tiårene. I norsk sammenheng er det særlig de internasjonale prosjektene "Arctic Modernities" og "Arctic Discourses", ledet fra UiT Norges arktiske universitet og finansiert av Norges forskningsråd, som har vært toneangivende. Begge har resultert i vesentlige utgivelser om det litterære Arktis, og flere av bidragsyterne til The Arctic in Literature for Children and Young Adults har da også vært tilknyttet ett eller begge prosjekter. Kanskje har barne- og ungdomslitteraturen meldt seg som en hvit flekk i løpet av disse prosjektene? Det er i alle fall gledelig at denne antologien vier seg fullt og helt til tekster for barn og unge, for etter endt lesning er det ingen tvil om at det her er enormt mye å hente for bedre å forstå mangfoldet og kompleksiteten i de litterære fremstillingene av Arktis.

Bidragene er fordelt på tre tematiske og til dels overlappende seksjoner: "Polar History and Its Transformations", "Indigenous and

(C2020 J. S. Kaasa. This is an Open Access article distributed under the terms of the Creative Commons Attribution-Noncommercial 3.0 Unported License (http://creativecommons.org/ licenses/by-nc/3.0/), permitting all non-commercial use, distribution, and reproduction in any medium, provided the original work is properly cited.

Citation: Barnboken - tidskrift för barnlitteraturforskning/Barnboken - Journal of Children's Literature Research, Vol. 43, 2020 http://dx.doi org/10.14811/clr.v43.531 
Localized Arctics", og "Arcticity and Imaginary Arctics". Slik Hansson skriver i innledningen, følger kapitlene en utvikling der Arktis går fra å være et fiendtlig sted man skal overvinne, typisk innenfor en maskulin heltediskurs, til et hjemliggjort sted der barnet kan lære og vokse, og videre, i tråd med en stadig sterkere vektlegging av økologiske perspektiver, et sårbart sted som må beskyttes og bevares, og som blir emblematisk for de globale klimaendringene. Slik Hansson også påpeker, er ikke disse utviklingslinjene rettlinjede. De grove linjene skissert over, er nettopp bare grove linjer. Gjennom hvert av bidragene viser antologien hvordan fremstillingene av Arktis inngår i uregelmessige relasjoner til det historiske, politiske og estetiske, så vel som til de omskiftende idealene for hva barne- og ungdomslitteraturen skal være.

Antologiens første del om polarhistoriens foranderlighet, innledes av Anka Ryalls kapittel "Polar Icon? Fridtjof Nansen for Children and Young Adults". Her peker Ryall på hvordan barne- og ungdomslitteraturens fremstillinger av Fridtjof Nansen både i ord og bilder nyanserer, og til og med undergraver hans status som polarhelt. Ryall viser dermed frem den subversive kraften som ligger i disse tekstene, og hvordan de bidrar til endringer i polarheltediskursen. Tanken om barne- og ungdomslitteraturens subversive potensial videreføres i det påfølgende bidraget av Silje Gaupseth om en lite diskutert tekst av den kanadiske polarforskeren Vilhjalmur Stefansson. I sin lesning av Stefanssons og Violet Irwins Kak, the Copper Eskimo (1924), argumenterer hun for at domestiseringen av Arktis er et pedagogisk grep for et vestlig publikum som inngår i romanens koloniale diskurs. Hjemliggjøringen av Arktis er også en viktig tematikk i Lena Aarekols tekst om Josephine Diebitsch-Pearys enormt populære bøker om datteren i The Snow Baby (1901) og Children of the Arctic (1903), der hun utforsker problemstillinger koblet til kjønn og etnisitet. Polarhistoriens foranderlighet kommer til uttrykk ikke bare i fremstillingen av mennesker: i sin gjennomgang av isbjørnen $\mathrm{i}$ nordisk barnelitteratur fra Rasmus Lølands tekst Kvitebjørnen (1906) og frem til i dag, demonstrerer Henning Howlid Wærp hvordan isbjørnen gjøres representativ for ulike diskurser og forestillinger om Arktis. Mange av verkene Wærp tar for seg, er lite omtalt i dag, og dette er en gjennomgående kvalitet og styrke ved hele antologien: ved å fokusere på tekster som befinner seg i randsonen av det vi vanligvis tenker på som polarlitteratur, bidrar kapitlene selv til den subversive kraften som de finner i kildematerialet.

Den andre delen i antologien tematiserer i større grad lokaliserte diskurser om Arktis, og flere av bidragene har med det en særlig 
vektlegging av urfolksperspektiver. Overordnet går denne delen inn i friksjonene som finnes i interne og eksterne perspektiver på Arktis, og diskuterer disse opp mot politiske og ideologiske forestillinger om kjønn og etnisitet. Ingeborg Høvik undersøker hvordan R.M. Ballantyne etablerer Arktis som et handlingsrom for jenter i sin spenningsroman Ungava (1857), men påpeker hvordan dette perspektivet svekkes, både i illustrasjonene som fremmer tradisjonelle kjønnsroller og i resepsjonen der den kvinnelige hovedpersonens handlekraft underspilles. Også JoAnn Conrad legger vekt på materialitet og resepsjon i sitt kapittel om reiser til Lappland i svenske barnebøker fra det sene 1800-tallet til midten av 1900-tallet. Her setter hun den gjennomgående annengjøringen (othering) av landet og samene som bebor det i sammenheng med svensk nybyggermentalitet og ser den fortsatte (re)sirkuleringen av rasistiske forestillinger i lys av sosiopolitiske og tekstkulturelle forhold. I en litt annen støpning, gransker Tiffany Johnstone gnisningene mellom beskrivelser utenfra og innenfra i den inuittiske forfatteren Michael Arvaarluk Kusugaks bøker og argumenterer for at Kusugak trekker veksler på, men også undergraver eurovestlige stereotypier, og dermed bidrar til å "gjenforestille" (reimagine) seg Arktis. Et lignende resonnement finner vi i Lill Tove Fredriksens kapittel "Imagination and Reality in Sami Fantasy". Her viser hun hvordan samisk mytestoff er virksomt i tematiseringen av samtidens økologiske problemstillinger i Máret Ánne Saras fantasyromaner Ilmmiid gaskkas (2013) og Doaresbealde doali (2014), med en informativ gjennomgang av samisk barnelitteratur i Norge som bakteppe. I delens siste kapittel, undersøker Silje Solheim Karlsen fremstillingen av unge kvinnelige karakterer i norske ungdomsbøker satt til Svalbard, utgitt i perioden fra sent 1930-tall til tidlig 1970-tall, og ser på hvilke følger det arktiske livet som dannelsesprosjekt har for konvensjonelle kjønnsroller.

Som Hansson skriver innledningsvis, setter antologien seg fore å si noe om en "arktisitet" som overskrider det geografiske: "The imaginary Arctic, or the idea of 'Arcticity' [...] could be said to inform works that are not set in the Arctic region per se but employ iconic phenomena like snow, ice, cold, the aurora, shamanism, and so on to make metaphorical points" (2). De fleste bidragene omhandler likevel tekster som er satt til det geografiske Arktis. Antologiens tredje og siste del legger større vekt på det imaginære Arktis og de fem bidragene her belyser hvordan denne diskursen opptrer, virker og forandrer seg. Heidi Hansson utforsker fleksibiliteten i tropen om Arktis som kvinne, slik den opptrer i både faktiske og metaforiske landskaper, gjennom varianter av H.C. Andersens "Snedronningen" 
(1844) i engelskspråklige verker frem til Elsa i Disney-filmen Frost (2013). I sin analyse av den finske fortellingen "Sampo Lappelill: En saga från Lappland" (1860) av Zacharias Topelius, ser Toni Lahtinen fremstillingen av Lappland som et mytisk og fjernt sted i lys av impulser fra nasjonalromantikken og kristne eventyr, og leser Sampos mytiske reise i flukt med kristningen av Lappland. Johan Schimanskis kapittel om Arthur Ransomes Winter Holiday (1933), der en gruppe barn skaper sitt eget Arktis i nord-engelske Lake District, er kanskje det kapittelet som tydeligst tematiserer implikasjonene av forflytninger og forskyvninger av det arktiske landskapet, og Schimanski argumenterer for hvordan de engelske barna gjennom det imaginære Arktis skaper seg et rom som virker utvidende, ikke minst på tradisjonelle kjønnsmønstre. Kirsti Pedersen Gurholt vektlegger også kjønnsroller innenfor det arktiske, men i et annet medium og i en annen tid. I sitt bidrag om norske TV-serier for barn og unge som fremstiller unge jenter i Arktis, undersøker hun hvordan den tradisjonelt maskuline heltediskursen og oppdagertradisjonen revideres og trer inn i nye former. Maria Lindgren Leavenworths kapittel om tre ungdomsbøker fra 2000-tallet som befinner seg på ulike steder innen spekteret av det realistiske, fantastiske og spekulative, avslutter antologien. Med Sara Ahmeds begrep "queer moments" som omdreiningspunkt analyserer Lindgren Leavenworth passasjer der karakterenes mulighet for å orientere seg fysisk og eksistensielt destabiliseres, og viser hvordan tekstene utvider Arktis' rolle og funksjon i litterære fremstillinger.

Forflytningene og forskyvningene som særlig tas opp i denne siste delen, men også i antologien som helhet, tydeliggjør endringene i de betydninger og verdier som er blitt tillagt det arktiske. De setter dessuten i spill hvordan det faktiske og fiktive er virksomt i fremstillingene av Arktis. Det er betegnende, slik Hansson skriver i introduksjonen, at mange av de senere representasjonene av Arktis er fantastiske heller enn realistiske, og at dette muliggjør et spenn av fortellinger som på ulike måter belyser samtidige problemstillinger (22). Men det fantastiske må også forstås i forlengelsen av tidligere representasjoner av Arktis. For eksempel er Jules Vernes' Kaptein Hatteras (1866) representativ for en litteratur om Arktis der vitenskapsdiskurser og polarhistorie flettes sammen med det eventyrlige og utrolige, slik tilfellet også er i flere av både de eldre og nyere tekstene som studeres i denne samlingen.

Mange av de perspektivene som møter oss i antologien, er de samme som i andre utgivelser om fremstillinger av det arktiske spesielt og det nordlige generelt, og bidragsyterne knytter diskusjonene an 
til spørsmål om kjønn, etnisitet, kolonialisme, religion og økologi, for å nevne noe. Dette er alle vesentlige tilnærminger, og de får ny relevans her når de møter tekster skrevet for barn og ungdom, hvorav de fleste tidligere har vært nedvurdert og derfor viet liten akademisk interesse. En tilnærming som ikke får særlig plass her, er imidlertid spørsmålet om hvem barnet er i og utenfor disse tekstene. Antologien setter seg riktignok ikke som mål å ta i denne problemstillingen, selv om den finnes implisitt $i$ tematiseringen av barnets relasjon til naturen og av barnet som natur. Jeg tror likevel at en tydeligere og mer uttalt bevissthet rundt dette kunne være nyttig for enda bedre å forstå Arktis i barne- og ungdomslitteraturen. I likhet med forestillingene om det arktiske, er også barn, barndom og barnelitteratur foranderlige kategorier som er påvirket av en rekke diskurser og kontekster, noe som utvilsomt spiller inn i litterære og faktiske skildringer av det arktiske og av barnet i Arktis. Denne dynamikken mellom barnet som en historisk og sosial kategori og fremstillingene av Arktis kunne gjerne ha fått enda større plass i antologien.

Det er likevel ingen tvil om at denne utgivelsen gir verdifulle analyser og diskusjoner av det mangfoldet og kompleksiteten som preger Arktis og fremstillingene av det arktiske i barne- og ungdomslitteraturen. Slik Hansson skriver i introduksjonen: "New stories will continue to challenge received patterns and master narratives by drawing attention to the plurality of Arctics: mythical, urban, wild, everyday, fantastic, threatened, beautiful and frightening, but never simple" (22). Med dette oppfyller antologien også en annen viktig oppgave: den viser hvordan barne- og ungdomslitteraturen er helt sentral for å forstå Arktis som motiv og setting, som litterær og kulturell idé, og hvordan de barnelitterære representasjonene ikke bare overtar og trekker veksler på allerede eksisterende forestillinger, men omdanner og fornyer dem. Samtidig får antologien frem hvordan noen forestillinger er mer slitesterke enn andre, $\mathrm{i}$ barne- og ungdomslitteraturen så vel som i tekster for voksne. Den arktiske vinteren synes for eksempel å være langt hyppigere skildret enn den arktiske sommeren. Kanskje har snøen og isen en større metaforisk kraft som bedre korresponderer med det vi vil og trenger at Arktis skal være?

Hanssons, Lindgren Leavenworths og Ryalls samling fyller et kunnskapshull samtidig som den åpner opp og legger grunnlaget for å tenke andre tilnærminger som i enda større grad kan favne om det mangfoldige Arktis og fremstillingene av det. Bidragsyterne i antologien er basert i Norge, Sverige, Finland, USA og Canada - alle land som har geografisk tilknytning til Arktis, riktignok avhengig 
av hvilke avgrensninger vi legger til grunn - og de skriver i første rekke om tekster fra disse landene. Hvis vi holder fast ved ideen om Arktis som et mentalt sted hvis meningsdannelse ikke kan begrenses til det geografiske, vil kanskje neste steg kunne være å utvide tilnærmingen ytterligere ved å innlemme forskere og litteratur fra geografiske og språklige områder som vi i mindre grad forbinder med det arktiske? En slik fortsettelse vil i alle fall være i tråd med tanken om det "globale Arktis" som har vokst frem særlig innenfor geopolitikken de siste årene og som henviser til et analytisk redskap og forskningsmetode som bedre vil egne seg til å avdekke de komplekse, globale kontekstene for Arktis. En slik fortsettelse vil også være i tråd med de transnasjonale anslagene som det finnes stadig flere av i barnelitteraturforskningen i dag. Den som vil sette i gang med et slikt arbeid kommer imidlertid ikke utenom The Arctic in Literature for Children and Young Adults.

Janicke S. Kaasa

Postdoktor i allmenn litteraturvitenskap

Universitetet i Oslo 